The research program of the Center for Economic Studies (CES) produces a wide range of theoretical and empirical economic analyses that serve to improve the statistical programs of the U.S. Bureau of the Census. Many of these analyses take the form of CES research papers. The papers are intended to make the results of CES research available to economists and other interested parties in order to encourage discussion and obtain suggestions for revision before publication. The papers are unofficial and have not undergone the review accorded official Census Bureau publications. The opinions and conclusions expressed in the papers are those of the authors and do not necessarily represent those of the U.S. Bureau of the Census. Republication in whole or part must be cleared with the authors.

\title{
The Census of Construction Industries Database
}

\author{
By \\ Mark A. Calabria, Ph.D.* \\ Joint Center for Housing Studies \\ Harvard University \\ 79 John F. Kennedy Street \\ Cambridge, MA 02138
}

(617) 495-7908

CES 98-10

August 1998

All papers are screened to ensure that they do not disclose confidential information. Persons who wish to obtain a copy of the paper, submit comments about the paper, or obtain general information about the series should contact Sang V. Nguyen, Editor. Discussion Papers, U.S. Bureau of the Census, Center for Economics Studies, Room 211, Washington Plaza II, Washington, D.C. 20233-6101, (301-457-1882) or INTERNET address snguyen@ census.gov. 


\begin{abstract}
$\underline{\text { Abstract }}$
The Census of Construction Industries (CCI) is conducted every five years as part of the quinquennial Economic Census. The Census of Construction Industries covers all establishments with payroll that are engaged primarily in contract construction or construction on their own account for sale as defined in the Standard Industrial Classification Manual. As previously administered, the CCI is a partial census including all multi-establishments and all establishments with payroll above $\$ 480,000$, one out of every five establishments with payroll between $\$ 480,000$ and $\$ 120,000$ and one out of eight remaining establishments. The resulting database contains for each year approximately 200,000 establishments in the building construction, heavy construction and special trade construction industrial classifications. This paper compares the content, survey procedures, and sample response of the 1982, 1987 and 1992 Censuses of Construction.
\end{abstract}

Keywords: microdata, construction, economic census

*I wish to thank Al Nucci, Susan Hostetter, Tamara Cole, Pat Horning, Eric Belsky and Robert Schafer for their comments on an earlier draft. The comments, views and conclusions represented in this paper do not reflect those of either the Joint Center for Housing Studies or Harvard University. 


\section{INTRODUCTION}

The recent availability of establishment level microdata at the Census Bureau has spawned a renewal in the study of industry dynamics. The bulk of this research has utilized the Census Bureau's Longitudinal Research Database (LRD), which is housed at the Census Bureau's Center for Economics Studies. In response to many of the insights and observations that have evolved from this analysis, the Census Bureau is currently encouraging the expansion of the LRD, which contains only manufacturing establishments, into a database containing all nonfarm business sectors. This new database, the Longitudinal Business Database (LBD) will be built from the various economic census data files. One of the first sectors outside of manufacturing to receive attention is construction.

In 1992, the construction industry had over 573,300 establishments with payroll, with over $4,674,000$ workers, $3,596,000$ of which were construction workers. Total value of construction work performed in 1992 was $\$ 529$ billion. By comparison, the manufacturing sector in 1992 was made up of approximately 370,000 establishments, with close to 19 million workers, about 12 million of which were production workers. The manufacturing sector had a total value of shipments of over \$3 trillion in 1992.

This paper documents the contents, survey procedures, and survey response of the 1982, 1987, and 1992 Censuses of Construction Industries, which currently constitute the Census of Construction Industries Database. Its primary purpose is to provide users with a comparison of the datasets across years, outline some of the strengths and weaknesses of the data, and allow 
potential users to gauge the database's potential to answer relevant research questions.

Section II gives a brief introduction to the Census Bureau's Economic Census program, which includes the Census of Construction Industries (CCI). Section III offers the reader more detailed information on the CCI. Section IV discusses the differences between the 1982, 1987, and 1992 versions of the CCI. Section V briefly discusses procedures for linking establishments across the three years. Section VI highlights some of the strengths and weaknesses of the CCI. Section VII outlines how the reader may gain access to the CCI.

\section{THE ECONOMIC CENSUS PROGRAM}

Title 13 of the United States Code (sections 131, 191 and 224) directs the Census Bureau to take an economic census every 5 years, in years ending with 2 or 7 . In addition to the construction sector discussed here, the economic census also covers the following areas: Retail Trade, Wholesale Trade, Services Industries, Financial, Insurance and Real Estate Industries, Transportation and Communications, Manufactures, and Mineral Industries. Special programs also cover enterprise statistics and minority and women-owned businesses.

The economic census has been conducted every five years since 1967. Information for the above sectors was also collected simultaneously in 1962, 1958, and 1954; with the exception of Transportation and Communications, and Financial, Insurance and Real Estate Industries, which first appeared in 1992. Previous economic censuses were conducted at varying intervals for various sectors of the economy. The first economic census that was conducted separately from the decennial population census was for the manufacturing sector in 1905. The first census of 
business was conducted in 1930, covering retail trade, wholesale trade, construction, and manufacturing. The economic census was broadened further in 1933 to include some of the services industries. The economic census excludes agriculture and government, which are covered in other census programs.

Since 1967, administrative records have been substituted for the surveying of very small firms and nonemployer establishments. In most industry sectors, a mailed questionnaire is sent to all establishments above a chosen size (either in terms of payroll or employees), while administrative data are used for all establishments below that level. The CCI, however, samples firms below a minimum size (to be discussed) while using administrative data for a portion of the nonmail sample. In these instances, administrative data for payroll, employment and sales are taken from IRS/SSA records and used to impute the remainder of the establishment record.

The economic census collects a wealth of establishment level data used in the estimation of such macroeconomic measures as gross domestic product, input/output measures, and production and price indexes. In addition to collecting data on employment, wages and general measures of business value (e.g., value of sales, shipments, and work performed), the economic census also collects detailed data on product lines, labor costs (e.g., wages and fringe benefits), and the value of capital and depreciable assets. An example 1992 construction questionnaire is attached as appendix C. It offers some examples of information commonly collected by the economic census program, although the reader should keep in mind that questionnaires can differ greatly across industries and standard industrial classifications.

For greater detail on the Economic Census program, the reader is referred to the Census 
publications; Guide to the 1992 Economic Census and Related Statistics, and History of the 1992 Economic Census.

\section{THE CENSUS OF CONSTRUCTION INDUSTRIES PROGRAM}

The Census of Construction Industries (CCI) is conducted every five years as part of the Economic Census. The CCI covers industries classified as building construction (SIC 15), heavy construction (SIC 16) and specialty trade construction (SIC 17). A brief discussion of these each of industry classifications follows:

SIC 15: Building construction by general contractors or by operative builders. SIC 15 establishments are engaged primarily in the construction of residential structures, and commercial buildings such as office buildings and warehouses (sometimes referred to as vertical construction). This group also includes those establishments generally referred to as "home builders" which are classified in SIC 152. Operative builders (SIC 1531) are those who build on their own account for sale and are often referred to as "speculative builders".

SIC 16: Heavy construction general contractors. SIC 16 establishments are engaged primarily in the construction of nonbuilding construction projects (sometimes referred to as horizontal construction). These include the construction of highways, bridges, pipelines, sewer and water lines, and marine construction.

SIC 17: Construction by special trade contractors. SIC 17 are engaged in both vertical and horizontal construction projects. Their numbers are, however, heavily dominated by those engaged in the specialties of plumbing, heating and air-conditioning (SIC 171); electrical work 
(SIC 173); and other building-related trades such as masonry and stone work (SIC 1741) and carpentry work (SIC 1751).

It is important to keep in mind, especially when comparing CCI figures to other construction statistics, that not all establishments performing 'construction' are included in the CCI. The two most important types of establishments performing some construction work that are absent from the CCI are 1) 1,350,000 establishments without payroll, 1,100,000 of which are categorized as special trade contractors (SIC 17), largely carpentry and painting establishments, and 2) force account construction, which consists of construction performed by establishments and firms for their own use. Force account construction includes such activities as investment builders who build structures on their own account for rent (classified under Real Estate, SIC 651) and plant maintenance and repair performed by employees of a manufacturing establishment. Establishments without payroll are not required by law to fill out census forms, and hence, are not mailed census questionnaires under the economic census program.

The CCI collects information, at an establishment level, for a wide variety of variables including: value of work performed, value of work subcontracted, expenditures on wages, fringe benefits, fuels, electricity, materials, number of construction and nonconstruction employees, values of assets and capital expenditures.

The CCI is, however, a partial census. The CCI is a complete census of multiestablishment establishments (approximately 10,800 in 1992), and a census of establishments with $\$ 480,000$ or more in payroll (approximately 40,657). The CCI samples all other establishments as follows: a) establishments with $\$ 120,000$ to $\$ 480,000$ in payroll proportionate to their size but 
with a base rate of 1 in 5, and b) establishments with payroll under $\$ 120,000$ at a base rate of 1 in 8. The complete census of multi unit and large payroll single establishments comes to about 51,000 . These amount for a little under ten percent of the establishment universe, but cover $65 \%$ of payroll employment and 63\% of the value of construction work performed in 1992.

The sampling frame for the CCI is the Bureau's Standard Statistical Establishment List (SSEL). Of the 547,000 single unit establishments classified on the 1991 SSEL as construction companies, 132,411 were included in the mail sample for the $1992 \mathrm{CCI}$, in addition to the 10,836 multi unit establishments identified on the 1991 SSEL as operating in construction. In addition to these, another 49,287 establishments were added to the database for 1992 from establishments originally unclassified or misclassified. Table 1, below, lists the universe and sample counts for the 1992 CCI. The figures in Table 1 differ from the frame described above because of establishment deaths from 1991 to 1992 (not included in 1992 sample) and births in 1992.

Table 1

Sample and Universe Counts of 1992 CCI by Payroll

\begin{tabular}{lll}
\hline Establishment Sample Origin & 1992 Universe & 1992 CCI
\end{tabular}

Multi unit establishments

10,634

10,566

Single Units

Payroll \$480,000 and greater

39,977

37,345

Payroll between $\$ 120,000$ and $\$ 480,000$

106,807

41,779

Payroll under \$120,000

415,433

128,613 
Source: Author's calculations from CCI database.

The probability sample for smaller single unit establishments is a three strata random sample formed upon the basis of 1) four digit SIC, 2) same geography (state or MSA), and 3) size class. Some deviations from this sampling scheme were implemented to ensure that the standard error of payroll within state-MSA by SIC codes was between 1.5 and 15 percent. Due to the small number of establishments within the SICs 1622, 1795 and 1796, all establishments in these SICs were included in the mailout.

This sampling scheme results in the following breakdown of establishments in 1992: 1) approximately 89,000 establishments which constitute $19 \%$ of single-units with a payroll less than $\$ 480,000 ; 2)$ approximately 26,000 fourth quarter births; 3 ) approximately 44,000 establishments that were originally unclassified by SIC; and 4) approximately 14,000 establishments that were originally missclassified by SIC. In the latter three of these categories, all information except the administrative items is imputed.

In 1992, the response rates for the mailed questionnaire were: establishments with a payroll $\$ 480,000$ and greater -- $86.8 \%$, establishments with payroll between $\$ 120,000$ and $\$ 480,000$-- $83.1 \%$, establishments with a payroll under $\$ 120,000$-- $77.6 \%$, all multi unit establishments --86.3\%, all single establishments --81.5\%.

Researchers wishing to use only actual mail response data must be alert to the fact that 
characteristics, such as survival and growth, are likely to be correlated with size and affiliation, and proper care must be taken when interpreting results based solely upon mailed response data.

As with all the economic censuses a variety of questionnaires were mailed to different establishments in different SICs, in addition to the use of both a long and short form. The 1992 CCI made use of 22 different questionnaires. These included a short and long form for the following SIC groups: 15, 16, 171, 172, 173, 174, 175, 176, 178 and 179. Establishments with 1991 administrative payroll equal to or greater than $\$ 1,080,000$ all received the long form. For smaller establishments, half received the long form and half the short form. A form weight is included for the long form responses to allow for reasonable aggregates.

\section{DIFFERENCES BETWEEN THE 1982, 1987 AND 1992 CCI}

The basic difference between the three CCIs documented here is that a variety of questions that were asked in one census year but not in all census years. In addition, establishments in SIC 6552 are excluded from the 1992 CCI $^{1}$. The researcher should keep in mind that the reason for some questions having been dropped from the CCI was frequently based upon the low quality of responses to those questions. Some of the more important differences in the questionnaires are described below.

Questions asked on previous CCIs, but not on 1992 (and considered to be permanently dropped) are: 1) value of other land receipts, 2) number of hours worked by quarter, 3) receipts for sale of land, and 4) value of work in progress. 
Fields new to the 1992 CCI include 1) construction value, 2) value of speculative work, and 3) value of work for own use. Construction value can however be calculated for 1982 and 1987 from other variables found in the database in those years.

Data item availability across the three census years is summarized in appendix D, which lists the variable description and the corresponding variable name in each database.

\section{LINKING ESTABLISHMENTS ACROSS YEARS}

Linking establishments across years requires the matching of a common identifier variable. This section describes the identifiers available on the CCI and some of their limitations. For a detailed discussion of methods for linking establishments across years the reader is referred to Trager and Moore (1995). Appendix F contains a simple SAS routine for linking establishments across years in the CCI.

The following identification codes are generally available for each establishment: CFN, PPN, EIN, and OLDID. These are described below and form the basis for all efforts to link across census years. All the linking approaches involve some false matches.

All establishments in the Economic Census program have a variety of establishment and enterprise level identifiers. The most common of these is the Census File Number (CFN). For single unit establishments, the $\mathrm{CFN}$ is a ten digit code that starts with a 0 and is followed by a unique nine digit Employer Identification Number (EIN) which the establishment is required to

\footnotetext{
${ }^{1}$ SIC 6552 covers Land Subdividers and Developers, except cemeteries. Their inclusion in the CCI prior to 1992 resulted from the lack of a separate real estate (SIC 65) census prior to 1992.
} 
use when filing paperwork with the Social Security Administration (SSA) and/or the Internal Revenue Service (IRS). The establishment retains the same CFN until there is either a dissolution of the establishment or a change in ownership (in which case a new CFN may be assigned). For multi unit establishments the first six digits of the CFN refer to the enterprise (company or firm), while the last four refer to the individual location or establishment. The multi unit CFN is assigned by the Census Bureau. When linking enterprises, it is suggested that data first be aggregated to the enterprise level (sum by the first six digits of the $\mathrm{CFN}$ ), and then linked across years by the first six digits of the CFN. Single establishments, and establishment components of multi unit establishments, can be linked across years by a matching of the CFN.

As mentioned above the CFN will generally, but not always, change in the case of a change in ownership or reorganization of the establishment. If the researcher is interested in tracking the survival of an establishment regardless of ownership change, or is interested in examining issues of ownership change, the CFN will fail to link all relevant establishments across years. In these instances linking should be accomplished by also using the establishment's permanent plant number (PPN) and/or OLDID, which is an establishment's CFN prior to merger or reorganization.

When an establishment appears in the Economic Census or Standard Statistical Establishment List (SSEL) for the first time, it is assigned both a CFN and a PPN. In theory, the PPN corresponds to the establishment's initial CFN number assigned at birth for single unit enterprises. This will not always be the case for multi-unit establishments due to a renumbering of multi-unit PPNs in 1986. Whereas the CFN is an ownership-based identifier, the PPN is a 
location-based identifier. However, in some cases where the establishment changes location, the PPN may also change. This is sometimes the case when an establishment moves to a new location in order to expand (or contract) the scale of its operations without any change in ownership. When an establishment undergoes both a change in ownership and location, say as a result of the consolidation of administrative operations, the prior establishment is considered to have died and both the CFN and PPN would change. An effort is made to record the expiring CFN as the OLDID variable. In these cases the OLDID may be used to track reorganizations.

Limitations and exceptions to the above linking procedures may occur for a variety of reasons. Other researchers (see Trager and Moore) have discovered that in many instance where a single unit establishment changes to a multi unit establishment, with a resulting change in CFN, the PPN is often also changed, making a link based upon those two variables ineffective. In these cases it is suggested that the researcher attempt matching Employer Identification Numbers across the years.

Another potential method for matching establishments is a business name match. In this case establishments with the same five-digit zip code (or other geographic identifier) are matched based upon concatenated alpha string matches. Similar methods can also be used for matchings based upon industrial classification and address or zip code identifiers. However, name, address and industrial classification matching, may result in a much higher rate of false matchings when compared to the preferred CFN/PPN matching. One potential benefit from name and address matching is that it may allow the researcher to account for changes in the CFN and PPN that do not reflect a death. In certain circumstances, the integrated use of these techniques may pay 
dividends.

Current research efforts have found that a simple CFN and PPN match yield surprising good results for the CCI when compared with efforts to match establishments in other sectors. This result, however, is subject to differences in sampling across the CCI years. A simple CFN link by establishment from the 1987 CCI to the 1992 CCI yielded a match (or survival) rate or only 26\%; whereas matching these same 1987 CCI establishments to the 1992 SSEL yielded a match rate of $73 \%$. The tradeoff between the degree of accuracy demanded and the potential safeguards to be taken against false matching is obviously a decision individual researchers must make for themselves.

Researchers unfamiliar with the construction industry or economic census definitions should be aware that what defines an establishment can be very different across industries and even firms within the same industry. The Census Bureau defines a construction establishment as "a relatively permanent office or other place of business where the usual business activities related to construction are conducted." Usual business activities would not include the actual performance of construction activities, but rather those administrative activities, such as the maintenance of employee records, that are conducted by the establishment. In most instances this will rarely be the same location as any particular construction project. In contrast, most manufacturing, retail and service establishments will conduct both their administrative and economic activities in the same location. These differences should be kept in mind when comparing the activities of establishments within construction to establishments in other industries. 


\section{STRENGTHS AND WEAKNESSES OF THE CCI}

The primary strength of the CCI is the wide range of questions and information contained in the database at an establishment level. On the other hand, its primary weaknesses for microdata analysis are the extent to which much of the data are imputed ${ }^{2}$ and the sampling coverage is biased toward larger and multi unit establishments. Many of the characteristics of the database are a result of a sample design and processing strategy which places an emphasis on the amount of value covered versus the number of records collected, with the goal of providing reliable estimates at an aggregate level.

As the reader can gather from the data dictionary and sample questionnaire included in the appendix to this paper, the CCI contains a wide variety of questions on the characteristics of individual construction establishments. In addition to detailed information on employment, payroll, geography and line of business information, the CCI contains a wealth of information on capital expenditures, depreciable assets, inventories, materials costs, and a range of other operating costs, such as electricity, fuels, labor benefits, rental/lease payments, purchased services and subcontracted work.

Another strength of establishment microdata is the ability to reclassify establishments and activities in a manner more conducive to a particular research question. Interesting questions about construction establishments are the division of their activities between residential and commercial, and the division of their activities between new construction and alterations and

\footnotetext{
${ }^{2}$ For 1992, the original keyed, unedited data is also available for mail respondents. The keyed data for prior years is believed to be lost.
} 
additions. Many questions about the variations of these divisions by firm and regional characteristics cannot be answer by referring to published aggregate information. For example, it is very difficult to determine from published tabulations how much of a particular industry group, say plumbers, are engaged in solely residential work, solely residential remodeling, or some of both. Access to establishment level microdata allows the researcher a much greater flexibility when categorizing establishments. Microdata also allows different measures of business activity. In published aggregates, all of the value of an establishment's activity is assigned to its primary SIC code, even if its secondary activities are quite substantial. Establishment microdata allows the researcher to take a greater look at establishments' other product and businesses lines.

One of the primary weaknesses of the $\mathrm{CCI}$ is the extent to which much of the information is imputed. Table A lists the response rates and universe estimates for the $1992 \mathrm{CCI}$ by four digit SIC. The response rate in this table indicates what percentage of the data, by record, is considered actual reported data ${ }^{3}$. The variance across industries is striking. While much of the heavy construction sector (SIC 16) has response rates in excess of 70\% (91\% for SIC 1622), the response rate for the SIC 15 and SIC 17 usually range in the 50s and 60s, with a low of 39\% in SIC 1751. In general, the percentage of records that are actual reported data is closely correlated with the size and affiliation of the establishment, which explains much of the variance across industries.

\footnotetext{
${ }^{3}$ This, of course, does not mean that none of the items on the record are imputed.
} 
Appendix G displays the mailed response rates to any particular item by 2 digit SIC for the $1992 \mathrm{CCI}^{4}$. These data are reported only for establishments that received and returned a questionnaire. For instance the first variable listed, $1^{\text {st }}$ Qtr. Construction Workers was answered by $81.3 \%$ of establishments in the SIC 15 group in 1992 that returned a questionnaire. Fortunately, Census Bureau research in a follow-up to the 1987 Economic Census indicates that the imputation procedures for payroll, sales and employment variables are similar to what the actual values are thought to have been (see Bailey, Jansto, and Smith). Although this research does indicate that the imputes tend to be biased upwards.

Economic Census establishment imputes are generally based upon the use of administrative data reported to the IRS or SSA for sales, payroll and employment. In all cases the administrative data for these items also appear in the CCI database. It is this researcher's opinion that those items most similar and highly correlated with the administrative data can be considered reliable in spite of the high rate of imputation for these variables. For instance, a value for total construction worker wages that is imputed from total administrative payroll is likely to be quite similar to the actual figure.

\section{ACCESS TO THE CENSUS OF CONSTRUCTION INDUSTRIES DATABASE}

The Bureau of the Census collects CCI data under Title 13 of the United States Code.

\footnotetext{
${ }^{4}$ The flag files containing the item impute codes for the 1987 and 1982 CCIs are believed to be lost. It can only be assumed that the 1992 flag figures are representative of the data for earlier years.
} 
Accordingly, access to the microdata is restricted in order to protect the confidentiality of census respondents. The 1982, 1987, and 1992 CCI databases are maintained at the Census Bureau's Center for Economic Studies. Raw data files are also available for 1977 and 1972. These files, however, have not undergone the more rigorous verification and testing that have been applied to the more recent years. It is anticipated that the $1997 \mathrm{CCI}$ will be available to researchers in the fall of 1999.

The procedure for obtaining access to this database begins with a proposal outlining the research plan, including the model and data to be used, hypothesis tests and funding possibilities. This allows CES to ascertain the feasibility of the research and the type of data analysis required. There are two principal methods of accessing the CCI database. One involves a contract with the Manufacturing and Construction Division for tabulations. The other requires a visit to CES's research laboratory in Washington, or one of CES's other regional data centers (currently in Boston and Pittsburgh). In the latter case the research plan must include some demonstrable benefits to the Census Bureau's data programs. In the latter case interested parties should direct correspondence to Chief, Center for Economic Studies, U.S. Bureau of the Census, Washington Plaza II, Room 211, Washington, DC 20233.

For more information on special tabulations, call 301-457-4680, or direct written inquiries to the Chief, Manufacturing and Construction Division, Bureau of the Census, Washington, DC, 20233. Special tabulations are prepared on a cost basis. 


\section{Description of Appendices}

\section{A. RESPONSE RATES AND UNIVERSE ESTIMATES BY 4 DIGIT SIC. Appendix}

A lists six columns. The first of which is a 4 digit SIC code. The $2^{\text {nd }}$ column presents the number of establishments in that SIC to which a questionnaire was mailed. The $3^{\text {rd }}$ column presents the number of establishments which returned a questionnaire. Column 4 is simply column 3 divided by column 2. Column 5 presents the number of establishments believed to be operating in the SIC in question. Column 6 is simply column 3 divided by column 5 .

B. DICTIONARY OF VARIABLES. Appendix B lists the variable names as they appear in the SAS database with a short description of each variable. Please note that although the establishment name (NAME) appears in the data dictionary and is collected on the census questionnaire, this variable will generally not be available to outside researchers.

C. SAMPLE QUESTIONNAIRE. Appendix C offers a sample long form questionnaire 
for the SIC 171 group. This questionnaire can be considered representative of the questionnaire for the remaining construction SIC codes. 1992 and 1997 questionnaires for the remaining construction SIC codes are on file at CES and are available upon request from Census' Construction and Manufacturing Division.

D. 1982, 1987 AND 1992 ITEM AVAILABILITY. Appendix D lists a brief description of the questionnaire items and the names under which they appear in the various years of the CCI database. If a year column is blank for any particular item, then that item is not available for the year in question.

E. SAMPLE SAS PROGRAM FOR CFN MATCHING. Appendix E offers a brief, simple SAS routine for linking establishments within the database by census file number, also known as the IDNUM. A collection of more detailed SAS routines for the database is on file at CES and can be made available to researchers using the CCI database.

\section{F. MAILOUT RESPONSE RATES BY 2 DIGIT SIC FOR 1992 CCI. Appendix F} displays by questionnaire item the percent of those establishments that returned a questionnaire and the percentage that responded to the item in question. This percentage does not reflect item responses that were later edited. Items that were skipped (left blank) by respondents were later imputed. Appendix F allows the potential research to gain some insight into the database's coverage of the industry by number of establishments.

\section{G. PERCENT OF MAILOUT TOTAL ACCEPTED WITHOUT EDIT OR IMPUTE}

BY 2 DIGIT SIC FOR 1992 CCI. Appendix G displays by questionnaire item the percent of those establishments that received a questionnaire and the percentage who responded and whose 
response to the item in question was accepted without change (edit or impute). The keyed data file for 1992 contains the actual responses. Appendix $\mathrm{G}$ allows the potential researcher to gauge how much of the data can be used after dropping imputes and/or edits.

H.UNWEIGHTED DESCRIPTIVE STATISTICS FOR 1992 CCI. Appendix H displays the mean, skewness and standard deviation for most of the numeric variables found on the 1992 Census of Construction. These statistics are presented unweighted, and hence, should not be compared to published statistics.

\section{References:}

Bailey, L., Jansto, E., and C. Smith. 1992. "An Evaluation of Imputed Data for Nonrespondents to the 1987 Economic Censuses Single-Unit Establishments," Census Working Paper in Survey Methodology.

Belsky, E., Calabria, M., and A. Nucci, "Survivorship in the Construction Industries: Evidence from the Census of Construction," Paper presented at the Regional Science Association International, Buffalo, New York, November 7, 1997.

Calabria, M. "A Picture of the Construction Industry," Housing Economics April 1997.

Caballero, R., E. Engel and J. Haltiwanger (1997): "Aggregate Employment Dynamics: Building from Microeconomic Evidence," in The American Economic Review; 87, 115-37.

Davis, S. and J. Haltiwanger (1995): Measuring Gross Worker and Job Flows; Working Paper, Milken Institute for Job and Capital Formation, California.

--------, --------, and S. Schuh (1996): Job Creation and Destruction; Cambridge: MIT Press.

Dunne, T., M. Robers and L. Samuelson (1988): "Patterns of Firm Entry and Exit in U.S. Manufacturing Industries," in Rand Journal of Economics; 19, 495-515. 
------- (1989): "The Growth and Failure of U.S. Manufacturing Plants," in Quarterly Journal of Economics; 104, 671-98.

Nucci, A., "The Characteristics of Business Owners Database," Center for Economic Studies Discussion Paper 92-7 (August 1992), U.S. Bureau of the Census.

Somerville, C. T., "The Contribution of Land and Structure to Builder Profits and Houses Prices," Journal of Housing Research, 7(1996)\#1:127-141.

Trager, M. and R. Moore, "Development of A Longitudinally-Linked Establishment Based Register March, 1992 Through April, 1995," Paper presented at the Joint Statistical Meetings of the American Statistical Association, Lake Buena Vista, Florida, August 1995.

U.S. Bureau of the Census. 1979. The Standard Statistical Establishment List Program. Bureau of the Census Technical Paper 44.

U.S. Bureau of the Census. 1987 Census of Construction Industries. Various industries series. 
Appendix A 
Variable Name

IDNUM

EINUM

OLDID

SERIAL

MAIL

BATCH

SEQNUM

FORM

TYPE
Description

Identification Number (CFN)

For Single unit establishments the first digit is 0. For Multi unit establishments the first six digits are the Alpha number and the last four digits identify the individual plant establishment of the company.

Employer Identification Number

The nine digit number assigned to the employer or other tax paying entity.

The CFN of the establishment before it merged with another and assigned a new CFN.

Serial Number (Microfilm Frame Number)

An eight digit number assigned to form upon receipt in J'ville.

Mail Code

$0=$ Non Mail

1,3,5 = Short form Cases and long form cases which did not have a chance of getting short form.

2,4,6 = Long form Cases which had a chance of getting a short form.

7 = ICT Intercensus Transfer-Long form with no chance of getting short form.

$9=$ Non Select large growth cases.

Batch Number

The number assigned the batch of documents as they are keyed in J'ville.

Sequence Number

The position within the batch.

Form Number

The form number which was mailed to the establishment was based on the digit SIC of the establishment. (Suffix of $8=$ Long form; $9=$ Short form.)

Form Type

1 = Long Form, 2 = Short Form. 
STATE Processing State Code - FIPSCODE.

DIV

Division Code:

$1=$ New England

$2=$ Middle Atlantic

$3=$ East North Central

$4=$ West North Central

$5=$ South Atlantic

$6=$ East South Central

$7=$ West South Central

$8=$ Mountain

$9=$ Pacific

REGION Region Code

$1=$ Northeast

$2=$ North central

$3=$ South

$4=$ West

MOST

Mailout State Code - FIPSCODE

CMSA Consolidated Metropolitan Statistical Area Code.

MSA

Metropolitan Statistical Area Code.

PLACE $\quad$ FIPS Place Code.

CTY

FIPS County Code.

MODIV

Mailout Division Code.

The census subject matter in which the establishment was located at time of mailout.

$1=$ Mining

$2=$ Construction

3 = Manufactures (Non-ASM)

$4=$ Transportation

$5=$ Wholesale

$6=$ Retail 
Appendix B - Data Dictionary for the Census of Construction Industries Database

$7=$ Services

$8=$ CAO's and auxiliaries

$9=$ Classification Card

SIC Standard Industrial Classification

Four digit code denoting the industry to which the establishment has been assigned.

SUBIND SIC Sub industry code.

Two digit code denoting a specific job within theindustry. (Subind of 95 indicates an ICT intoconstruction. Subind of 99 indicates a base dataimpute case.)

SICFLG SIC coding flag.

$0=$ Establishment successfully coded to 6-digit .

$1=$ Establishment successfully coded to 4 digit.

MOSIC

Mailout SIC Code (SIC code at time of mailout.)

MOSUB Mailout SIC subindustry code.

WGT

Establishment Weight (Five digits with 2 implied decimals.)

FORMWT Form Weight

Five digits with 2 implied decimals. Weight assigned to compensate for items missing on short form. All records will contain this weight but it will be 1.00 for those in which it was not required

OLDWGT Original Weight at time of sampling.

Five digits with 2 implied decimals.

REL Primary Release Flag.

$0=$ Case not released.

$1=$ Mail case edited and released

$2=$ Mail case edited and released under new CFN

$4=$ Converted to non mail release

$5=$ Administrative release of classification card

$6=$ Control file match ICT released

7 =Released with pseudo PDIV based on form number(due to administrative record SIC update after original form was mailed)

$9=$ Successor or predecessor of previous release 


\section{Appendix B - Data Dictionary for the Census of Construction Industries Database}

$\mathrm{B}=$ Successor of Complex edit ICT

$\mathrm{C}=$ Record released as nonmail case during non mail releasing operations.

$\mathrm{D}=$ Release of delinquent establishment during closeout operations.

REL2

Secondary Release Flag

$0=$ No supplemental information.

$1=$ Correction to previously released case.

$2=$ In scope complex edit ICT

$3=$ Out of scope complex edit ICT

CCSCOD

CCS Code (Coverage Control Source Code).

EOYCOD End of Year Code

$1=$ In business at end of year

$2=$ Not in business at end of year

ACTCOD Activity Code

$0=$ Active establishment

$1=$ Add - Establishment was added during current year processing.

$2=$ Delete - Establishment is out of business, sold or duplicate of another.

$3=$ Ghost - This id number is the predecessor of another MU ID number.

MODLID Model ID Number.

CFN of record imputed from if case imputed, otherwise field will be blank.

IMPUTE Impute Code

$0=$ Not imputed, actual reported data.

$1=$ Record imputed using a model.

$2=$ Record imputed with base data procedure.

IMPSIC Impute Sic Code

The Sic used to match response and non response records to pick a model.

IMPDIV Impute Division Code

A pseudo division code used to group like records for model imputation.

LGADMN Large Growth Administrative Data flag.

This flag identifies cases whose weight changed to 1 based on the increase size of their administrative data.

$0=$ Not large growth

$1=$ Select Cases, Large growth 


\section{Appendix B - Data Dictionary for the Census of Construction Industries Database}

$2=$ Nonselect Cases, Large growth

LGRESP Large Growth Response Data flag.

This flag identifies cases whose weight changed to 1 based on large values in response data.

PROFIT A flag indicating whether or not establishment passed the profit test ratio limits.

0 = failed initially

$1=$ passed initially

$2=$ passed initially, but data failed edit even with expanded multipliers.

3 = passed initially, but failed on last re-edit.

$4=$ failed initially and still failed on last re-edit

PRATIO Profit Ratio

The ratio of $(\mathrm{PR}+\mathrm{SO}+\mathrm{CM}) / \mathrm{TR}$

CYPR

Total Current Year Administrative Payroll

CYAR

Total Current Year Administrative Receipts

CYPR1Q Current Year 1st Qtr Administrative Payroll

CBPEMP 1st Qtr Employment from County Business Patterns.

LFO

Legal form of Organization

$0=$ Corporation

$1=$ Sole Proprietorship

$2=$ Partnership

$5=$ Government

$7=$ Unknown

$8=$ Tax Exempt cooperative

$9=$ Other

PWP

Proprietor or Working Partnership

$0=$ Not a PWP

$1=$ Sole Proprietorship

$2=$ Partnership 
Appendix B - Data Dictionary for the Census of Construction Industries Database

DATAFL

Data Flag

$0=$ No bracketed Items or Altered Stubs

$1=$ Bracketed Items only.

$2=$ Altered Stubs only.

$3=$ Bracketed Items and Altered Stubs.

PPN

PPN Number.

RLSDAT Release date

The date establishment was released from control file match to the division .

SICnn

SIC Code for year 19nn

SINDnn

Subindustry Code for year $19 n n$

PRnn

Total Payroll for year 19nn

IMPnn

Impute Code for year 19nn

$\mathrm{TR} n n$

Total Receipts for year $19 n n$

TE1nn

1st Qtr Employees for year 19nn

CW1

1st Qtr Construction Workers

CW2

2nd Qtr Construction Workers

CW3

3rd Qtr Construction Workers

CW4

4th Qtr Construction Workers

OE1

1st Qtr Other Employees

OE2

2nd Qtr Other Employees

OE3

3rd Qtr Other Employees

OE4

4th Qtr Other Employees

TE1

Total 1st Qtr Employees 
Appendix B - Data Dictionary for the Census of Construction Industries Database

TE2

TE3

TE4

ACW

AOE

ATE

TCW

TOE

TTE

OES

CWW

PR

PR1

WTDPR

LEGAL

VOLUNT

TLC

SO

$\mathrm{CM}$

ELEC
Total 2nd Qtr Employees

Total 3rd Qtr Employees

Total 4th Qtr Employees

Average Construction Workers

Average Other Employees

Average Total Employees

Sum of 4 Qtrs of Construction Workers

Sum of 4 Qtrs of Other Employees

Sum of 4 Qtrs of Total Employees

Other Employee Salaries

Construction Worker Wages

Total Payroll

1st Qtr Payroll

Weighted Payroll

Cost of Legally Required Programs

Cost of Voluntary Programs

Total Labor Costs for Fringe Benefits

Amount paid for work subcontracted out to other companies.

Payments for components, materials and supplies.

Electricity Costs 
Appendix B - Data Dictionary for the Census of Construction Industries Database

$\begin{array}{ll}\text { NATGAS } & \text { Natural Gas Costs } \\ \text { GASON } & \text { Gasoline and Diesel Fuel Cost for on Highway } \\ \text { GASOFF } & \text { Gasoline and Diesel Fuel Costs for off Highway } \\ \text { OTFUEL } & \text { Other Fuels Cost } \\ \text { TFUEL } & \text { Total Fuels Cost } \\ \text { RM } & \text { Payments for rental or lease of machinery } \\ \text { RS } & \text { Payments for rental or lease of structures } \\ \text { RT } & \text { Total payments for rental or lease } \\ \text { PSCOMM } & \text { Selected Purchased Services for communications } \\ \text { PSRM } & \text { Selected Purchased Services for repairs to machinery and equipment } \\ \text { PSRS } & \text { Selected Purchased Services for repairs to structures } \\ \text { PSTOTL } & \text { Total Selected Purchased Services. } \\ \text { BR } & \text { Receipts for Business work. } \\ \text { CV } & \text { Total Value of Construction work done. } \\ \text { TR } & \text { Total Receipts. } \\ \text { NCR } & \text { Net Construction Value (NCR = CV-SO) } \\ \text { VA } & \text { Value added (VA = TR-SO-CM-TFUEL-LR) } \\ \text { FRIVAT } & \text { construction }\end{array}$


Appendix B - Data Dictionary for the Census of Construction Industries Database

SL Percent of total construction value for work done on state and locally owned construction

SUBIN Percent of total construction value for work Subcontracted in from others.

GBS Gross Book Value of Depreciable Assets for structures and additions

SOURCE Source of Receipts Item.

GBM Gross Book Value of Depreciable Assets for machinery and equipment

GBT Total Gross Book Value of Depreciable Assets

GBS1 Gross Book Value of Depreciable Assets for structures at beginning of year

GBM1 Gross Book Value of Depreciable Assets for machinery at beginning of year

MR Percent of Construction value for machinery and repair

GBT1 Total Gross Book Value of Depreciable Assets at beginning of year

NS Capital Expenditures for New Structures

NM Capital Expenditures for New Machinery

NT Capital Expenditures for New Vehicles

US Capital Expenditures for Used Structures

UM Capital Expenditures for Used Machinery

TCE Total Capital Expenditures

GBSRET Gross Book Value of depreciable structures retired during year.

GBMRET Gross Book Value of depreciable machinery retired during year.

GBTRET Total Gross Book Value of depreciable assets retired during year.

DCS Depreciation charges for Structures and additions 


\section{Appendix B - Data Dictionary for the Census of Construction Industries Database}

DCM

DCT

INVnn

KOB1 (1)

KOB1 (2-24)

KOB1 (25)

KOBCNT

KOB2 (1)

KOB2 (2-24)

KOB2 (25)

CLSCNT

CLASS $(1,1)$

$\operatorname{CLASS}(2,1)$

CLASS $(3,1)$

CLASS $(4,1)$

CLASS

CLASS $(1,20)$

$\operatorname{CLASS}(2,20)$

$\operatorname{CLASS}(3,20)$
Depreciation charges for Machinery

Total Depreciation charges.

Total Inventory for year 19nn.

Kind of Business code for 1st entry

Kind of Business codes for 2nd to 24th entry

Kind of Business code for 25th entry

Number of Kind of business entries

Percent of total value for the 1st entry

Percent of total value for the 2nd to 24th entry

Percent of total value for the 25th entry

Number of entries for classification of construction work.

Type of construction code for the $1^{\text {st }}$ classification entry

Percent of total construction value for the 1st classification entry

Percent of total construction value for the 1st classification entry that was new construction

Percent of total construction value for the 1st classification entry that was additions and alterations

Sets of type of construction codes and percents

Type of construction code for the $20^{\text {th }}$ classification entry

Percent of total construction value for the 20th classification entry

Percent of total construction value for the 20th classification entry that was 


\section{Appendix B - Data Dictionary for the Census of Construction Industries Database new construction}

CLASS $(4,20) \quad$ Percent of total construction value for the 20th classification entry that was additions and alterations

NEW

Percent of total construction value for new construction

AA

Percent of total construction value for additions and alterations

HOMEST

Percent of total construction value for work performed in the state in which the establishment is located.

SCOUNT Number of states in which establishment did construction work.

WORKST(1) Percent of total construction value for work done in Alabama

WORKST(2-50) Percent of total construction value for work done for appropriate state, alphabetic order

WORKST(51) Percent of total construction value for work done in Wyoming

CENYR Census Year of file. 92=1992 Economic Census

NAME Establishment Name (Alpha)

CITY City Establishment Located (Alpha)

GENMP General Multiplier Used in editing

SAMPR Payroll used in Sampling

OPSTAT Operation status

$1=$ In operation

$2=$ Temporarily in seasonally inactive

$3=$ Ceased operation

$4=$ Sold or leased

NTOTAL Total new capital expenditures 
Appendix B - Data Dictionary for the Census of Construction Industries Database

MIB

UTOTAL

ALPHST

CR

SV

OV
Months in Business

Total used capital expenditures

Alpha state code in which establishment located

Receipts for Construction work

Value of speculative construction work

Value of construction work done for own use 
Appendix D - 1982, 1987, and 1992 CCI Item Availability

Questionnaire

Item Name By Year

Item 1992 1987

Identification Number (CFN)

IDNUM

IDNUM

IDNUM

Employer Identification Number

EINUM

EINUM

EINUM

CFN of the establishment before

it merged with another and

assigned a new $\mathrm{CFN}$

OLDID

ODLID

OLDID

Serial Number

SERIAL

SERIAL

SERIAL

Mail Code

MAIL

MAIL

MAIL

Batch Number

BATCH

BATCH

BATCH

Sequence Number

SEQNUM

SEQNUM

SEQNUM

Form Number

FORM

FORM

FORM

Form Type

TYPE

TYPE

TYPE

State FIPS

STATE

STATE

STATE

Division Code

DIV

DIV

DIV

Region Code

REGION

REGION

REGION

Mailout State Code - FIPS

MOST

MOST

MOST

CMSA Code

CMSA

CMSA

CMSA

MSA Code

MSA

MSA

MSA

FIPS Place Code

PLACE PLACE

PLACE

FIPS County Code

CTY

CTY

CTY

Mailout Division Code

MODIV

MODIV

MODIV

Standard Industrial Classification

SIC

SIC

SIC 
Appendix D - 1982, 1987, and 1992 CCI Item Availability

Questionnaire

Item Name By Year

Item

1992

1987

1982

SIC Sub industry code

SUBIND

SUBIND

SUBIND

SIC coding flag

SICFLG SICFLG

SICFLG

Mailout SIC Code

MOSIC

MOSIC

MOSIC

Mailout SIC subindustry code

MOSUB

MOSUB

MOSUB

6 digit SIC under 1982 SIC

coding rules

SICR82

Establishment Weight

WGT

WGT

WGT

Form Weight

FORMWT

FORMWT

FORMWT

Original Weight at

time of sampling

OLDWGT

OLDWGT

Primary Release Flag

REL

REL

REL

Secondary Release Flag

REL2

REL2

REL2

Coverage Control Source Code

CCSCOD

CCSCOD

CCSCOD

End of Year Code

EOYCOD

EOYCOD

EOYCOD

Activity Code

ACTCOD

ACTCOD

ACTCOD

Model ID Number

MODLID

MODLID

MODLID

Impute Code

IMPUTE

IMPUTE

IMPUTE

Impute Sic Code

IMPSIC

IMPSIC

IMPSIC

Impute Division Code

IMPDIV

IMPDIV

IMPDIV

Large Growth Administrative

Data flag

LGADMN

LGADMN 
Flag indicating whether or not establishment passed the profit test ratio limits

PROFIT

PRATIO

Profit Ratio

Number of Items reported

MDF value on raw data check

Number of Items unchanged

by Speer edit

MDF value on edited data check

Total Current Year

Administrative Payroll

Total Current Year

Administrative Receipts

Current Year 1st Qtr

Administrative Payroll

Joint Venture Code

Remarks Flag

Type of Construction

write-in simple edit

1st Qtr Employment from

County Business Patterns

Legal form of Organization

Proprietor or Working Partnership
CYAR

CYPR1Q

CYPR1Q

CYPR1Q

JOINT JOINT

REMARK

REMARK

REF91 REF91

CBPEMP

CBPEMP

CBPEMP

LFO

LFO

LFO

PWP

PWP

PWP 
Questionnaire

Item

Data Flag

PPN Number

Release date

1987 SIC Code

1987 Subindustry Code

1987 Total Payroll

1987 Impute Code

1987 Total Receipts

1987 1st Qtr Employees

1st Qtr Construction Workers

2nd Qtr Construction Workers

3rd Qtr Construction Workers

4th Qtr Construction Workers

1st Qtr Other Employees

2nd Qtr Other Employees

3rd Qtr Other Employees

4th Qtr Other Employees

Total 1st Qtr Employees

Total 2nd Qtr Employees
DATAFL

PPN

RLSDAT

SIC87

SIND87

PR87

IMP87 IMPUTE

TR87

TR

TE187 TE1

$\mathrm{CW}$

CW2

CW3

CW4

OE1

OE2

OE3

OE4

TE1

TE2
DATAFL

DATAFL

PPN

RLSDAT

SIC

SUBIND

PR

PPN

RLSDAT

RLSDAT

yea 
Appendix D - 1982, 1987, and 1992 CCI Item Availability

Questionnaire

Item Name By Year

Item

1992 1987

Total 3rd Qtr Employees

Total 4th Qtr Employees

Average Construction Workers

Average Other Employees

Average Total Employees

Sum of 4 Qtrs of

Construction Workers

Sum of 4 Qtrs of

Other Employees

Sum of 4 Qtrs of Total Employees

Other Employee Salaries

Construction Worker Wages

Total Payroll

1st Qtr Payroll

Weighted Payroll

Cost of Legally Required Programs

Cost of Voluntary Programs

Total Labor Costs for Fringe Benefits Other Land Receipts

$1^{\text {st }}$ Qtr. Hours Worked

$2^{\text {nd }}$ Qtr. Hours Worked
TE3

TE3

TE4

TE4

ACW

AOE

ATE

ATE

ATE

TCW

TCW

TCW

TOE

TOE

TOE

TTE

TTE

TTE

OES

OES

OES

CWW CWW

PR

PR

PR

PR1

PR1

PR1
WTDPR

LEGAL LEGAL

VOLUNT

LEGAL

VOLUNT

TLC

LROTH

HOURS1

HOURS2
HOURS1

VOLUNT

TLC

HOURS2 
$3^{\text {rd }}$ Qtr. Hours Worked

HOURS3

HOURS3

$4^{\text {th }}$ Qtr. Hours Worked

HOURS4

HOURS4

Total Hours Worked

THOURS

THOURS

Impute Inventory Flag for 1986

IMPIN6

Impute Inventory Flag for 1987

IMPIN7

Amount paid by establishment for work subcontracted out to other companies SO $\mathrm{SO}$ SO

Payments for components, materials and supplies CM

$\mathrm{CM}$

$\mathrm{CM}$

Electricity Costs

ELEC

ELEC

ELEC

Natural Gas Costs

NATGAS

NATGAS

NATGAS

Gasoline and Diesel Fuel

Cost for on Highwa

GASON GASON

GASON

Gasoline and Diesel Fuel

Costs for off Highway

GASOFF

GASOFF

GASOFF

Other Fuels Cost

OTFUEL

OTFUEL

OTFUEL

Total Fuels Cost

TFUEL

TFUEL

TFUEL

Payments for rental or lease of machinery

$\begin{array}{ccccc}\text { RM } & \text { RM } & & \text { RM } & \\ \text { RS } & & \text { RS } & & \text { RS }\end{array}$

lease of structures

RT

RT

RT

Total payments for rental or lease 
Selected Purchased Services

for communications

PSCOMM

PSCOMM

PSCOMM

Selected Purchased Services for

repairs to machinery and equipment PSRM

PSRM

PSRM

Selected Purchased Services

for repairs to structures

PSRS

PSRS

PSRS

Total Selected Purchased Services

PSTOTL PSTOTL

PSTOTL

Receipts for Business work

BR

BR

BR

Receipts for Sale of Land

LR

LR

Total Value of Construction work

CV

Receipts for Construction work

CR

CR

CR

Total Receipts

TR

TR

TR

Net Construction Value

NCR

NCR

NCR

Value added

VA

VA

VA

Percent of total construction value for work done on privately owned construction

PRIVAT

PRIVAT

PRIVAT

Percent of total construction value for work done on Federally owned construction FED

FED

FED

Percent of total construction value for work done on state and locally owned construction

SL

SL

SL

Source of receipts item SOURCE

Percent of total construction 
value for work Subcontracted

in from others

SUBIN

SUBIN

SUBIN

Gross Book Value of Depreciable

Assets for structures and additions

GBS

GBS

GBS

Gross Book Value of Depreciable

Assets for machinery and equipment

GBM

GBM

GBM

Total Gross Book Value of

Depreciable Assets

GBT

GBT

GBT

Gross Book Value of Depreciable Assets for structures at beginning of year

GBS1

GBS1

GBS1

Gross Book Value of Depreciable Assets for machinery at beginning of year

GBM1 GBM1 $\quad$ GBM1

Percent of Construction value

for machinery and repair

MR

MR

MR

Total Gross Book Value of

Depreciable Assets at

beginning of year

GBT1

GBT1

GBT1

Capital Expenditures for

New Structures

NS

NS

NS

Capital Expenditures for

New Machinery

NM

NM

$\mathrm{NM}$

Capital Expenditures for

New Vehicles

NT

NT

NT

Capital Expenditures for

Used Structures

US

US

US 
Appendix D - 1982, 1987, and 1992 CCI Item Availability

Questionnaire

Item Name By Year

Item 1992 1987

Capital Expenditures for Used Machinery

UM

UM

UM

Total Capital Expenditures

TCE TCE

TCE

Gross Book Value of depreciable

structures retired during year

GBSRET

GBSRET

GBSRET

Gross Book Value of depreciable

machinery retired during year

GBMRET GBMRET

GBMRET

Total Gross Book Value of

depreciable assets retired during year

GBTRETGBTRET

GBTRET

Depreciation charges for

Structures and additions

DCS

DCS

DCS

Depreciation charges for Machinery

DCM

DCM

DCM

Total Depreciation charges

DCT

DCT

DCT

Total Inventory for 1991

INV91

Total Inventory for 1992

INV92

Total Inventory for 1986

INV86

Total Inventory for 1987

INV87

Total Inventory for 1981

INV81

Total Inventory for 1982

INV82

Cost of Materials 1986

MAT86

Cost of Materials 1987

MAT87

Work in Progress 1986

WIP86

Work in Progress 1987

WIP87 
Questionnaire

Item

Kind of Business code for \#th entry

Number of Kind of business entries

Percent of total value for \#th entry

Number of entries for classification

of construction work

Type of construction code for

the nth classification entry

Percent of total construction

value for the 1st classification entry

Percent of total construction value for the 1 st classification entry that was new construction

Percent of total construction value for the 1 st classification entry that was additions and alterations

Percent of total construction value for new construction

Percent of total construction value for additions and alterations

Percent of total construction value for work performed in the state in which the establishment is located

Number of states in which establishment did construction work

Percent of total construction value for work done in Alabama
Item Name By Year 1987
1992
1982

KOB1\#

KOBCNT

KOB2\#

CLASS1NCLASS1N CLASS1N

$\begin{array}{lll}\text { CLASS2N } & \text { CLASS2N } & \text { CLASS2N }\end{array}$

$\begin{array}{lll}\text { CLASS3N } & \text { CLASS3N } & \text { CLASS3N }\end{array}$

CLASS4N CLASS4N

NEW NEW NEW

AA AA AA

HOMEST HOMEST HOMEST

$\begin{array}{lll}\text { SCOUNT } & \text { SCOUNT } & \text { SCOUNT }\end{array}$

WORKST(1) WORKST(1) WORKST(1) 
Appendix D - 1982, 1987, and 1992 CCI Item Availability

Questionnaire

Item Name By Year

Item 1992 1987

Percent of total construction value for work done for appropriate state,alpabetic order

WORKST(\#) WORKST(\#)

WORKST(\#)

Percent of total construction value for work done in Wyoming

WORKST(51) WORKST(51)

WORKST(51)

Census Year of file

CENYR

CENYR

CENYR

Establishment Name (Alpha)

NAME

NAME

City Establishment Located (Alpha)

CITY

CITY

General Multiplier Used in editing

GENMP

GENMP

GENMP

Payroll used in Sampling

SAMPR

SAMPR

SAMPR

Operation status

OPSTAT

OPSTAT

OPSTAT

NTOTAL

NTOTAL

NTOTAL

Months in Business

MIB

MIB 


\section{Appendix D - 1982, 1987, and 1992 CCI Item Availability}

Questionnaire

Item

Total used capital expenditures

Alpha state code in which establishment located

Value of speculative

construction work

Value of construction

work done for own use
Item Name By Year

1992 1987

1982

UTOTAL UTOTAL UTOTAL

ALPHST

ALPHST

SV

OV 


\section{Appendix E}

I* Thi s programlinks establishments across CCls - written by Mark Cal abri a*/

I i bname de 'd: \ user dat a\ sas dat a';

dat a a;

set de. fil el( keep=f i rmid);

run;

proc sort;

by fi rmid;

run;

dat $a b$;

set de. filel( keep=fi rmid);

run;

proc sort;

by firmid;

run;

dat a c;

mer ge $a($ i $n=x) \quad b($ i $n=y)$;

by fi rmid;

if $x=1$;

if $y=1$;

run; 


\begin{tabular}{|c|c|c|c|c|c|c|}
\hline 1st Qtr Construction Workers & 81.3 & & 90.7 & & 89.0 & \\
\hline 2nd Qtr Construction Workers & & 81.2 & & 90.8 & & 88.9 \\
\hline 3rd Qtr Construction Workers & & 81.1 & & 90.9 & & 89.0 \\
\hline 4th Qtr Construction Workers & 81.0 & & 90.8 & & 88.8 & \\
\hline 1st Qtr Other Employees & & 80.6 & & 90.1 & & 88.2 \\
\hline 2nd Qtr Other Employees & & 80.6 & & 90.6 & & 88.4 \\
\hline 3rd Qtr Other Employees & & 80.6 & & 90.6 & & 88.4 \\
\hline 4th Qtr Other Employees & & 80.3 & & 90.4 & & 88.0 \\
\hline Total 1st Qtr Employees & & 80.5 & & 90.2 & & 88.3 \\
\hline Total 2nd Qtr Employees & & 80.5 & & 90.5 & & 88.3 \\
\hline Total 3rd Qtr Employees & & 80.5 & & 90.6 & & 88.4 \\
\hline Total 4th Qtr Employees & & 80.4 & & 90.5 & & 88.2 \\
\hline Average Construction Workers & & 80.4 & & 90.3 & & 88.2 \\
\hline Average Other Employees & & 79.3 & & 89.5 & & 86.9 \\
\hline Average Total Employees & & 79.6 & & 89.7 & & 87.4 \\
\hline $\begin{array}{l}\text { Sum of } 4 \text { Qtrs of } \\
\text { Construction Workers }\end{array}$ & & 41.0 & & 60.5 & & 48.1 \\
\hline $\begin{array}{l}\text { Sum of } 4 \text { Qtrs of } \\
\text { Other Employees }\end{array}$ & & 40.4 & & 59.9 & & 47.3 \\
\hline Sum of 4 Qtrs of Total Employees & & 40.6 & & 60.1 & & 47.6 \\
\hline Other Employee Salaries & & 75.3 & & 86.6 & & 80.6 \\
\hline Construction Worker Wages & & 80.8 & & 90.3 & & 87.1 \\
\hline Total Payroll & & 92.3 & & 95.0 & & 91.6 \\
\hline 1st Qtr Payroll & 64.1 & & 75.4 & & 63.9 & \\
\hline
\end{tabular}


Appendix F - Mailout Response Rates by 2 digit SIC for 1992 CCI

Questionnaire

SIC by Response Percent

Item 1500

1600

1700

Cost of Legally Required Programs

51.8

70.9

58.6

Cost of Voluntary Programs

50.2

69.1

56.6

Total Labor Costs for Fringe Benefits

50.5

69.5

57.1

Amount paid by establishment for work subcontracted out to other companies

90.1

87.5

Payments for components,

materials and supplies

80.4

87.6

85.0

Electricity Costs

77.0

85.9

82.1

Natural Gas Costs

72.8

79.9

76.7

Gasoline and Diesel Fuel

Cost for on Highway

76.6

85.3

82.0

Gasoline and Diesel Fuel

Costs for off Highway

71.8

83.0

75.6

Other Fuels Cost

70.9

80.1

74.7

Payments for rental or lease of machinery

68.6

Payments for rental or lease of structures

66.8

55.8

Total payments for rental or lease

100.0

100.0

100.0

Selected Purchased Services

for communications

50.7

69.4

57.6

Selected Purchased Services for repairs to machinery and equipment 50.1

69.0

56.6 
Appendix F - Mailout Response Rates by 2 digit SIC for 1992 CCI

Questionnaire

SIC by Response Percent

Item 1500

1600

1700

Selected Purchased Services

for repairs to structures

48.3

65.9

54.4

Total Selected Purchased Services

100.0

100.0

100.0

Receipts for Business work

75.3

82.4

78.8

Total Value of Construction

work done

78.9

88.2

84.1

Receipts for Construction work

82.7

91.5

89.2

Total Receipts

93.4

94.3

92.5

Net Construction Value

99.9

99.9

99.8

Percent of total construction

value for work done on privately owned construction

50.3

59.0

56.5

Percent of total construction value for work done on Federally owned construction

17.4

29.5

Percent of total construction value for work done on state and locally owned construction

52.2

30.8

Percent of total construction value for work Subcontracted in from others

50.4

68.7

56.9

Gross Book Value of Depreciable Assets for structures and additions Gross Book Value of Depreciable Assets for machinery and equipment

35.2

49.4

37.3

40.9

59.6

45.2 
Appendix F - Mailout Response Rates by 2 digit SIC for 1992 CCI

Questionnaire

SIC by Response Percent

Item 1500

1600

1700

Total Gross Book Value of

Depreciable Assets

42.0

59.7

46.1

Gross Book Value of Depreciable

Assets for structures at beginning

of year

38.8

53.6

41.8

Gross Book Value of Depreciable

Assets for machinery at beginning

of year

44.5

63.8

49.6

Total Gross Book Value of

Depreciable Assets at

beginning of year

44.2

62.1

48.8

Capital Expenditures for

New Structures

36.3

49.2

38.8

Capital Expenditures for

New Machinery

40.4

58.4

44.5

Capital Expenditures for

New Vehicles

41.1

57.9

45.1

Capital Expenditures for

Used Structures

34.6

46.5

36.8

Capital Expenditures for

Used Machinery

38.1

56.2

42.1

Gross Book Value of depreciable structures retired during year

46.6

36.9

Gross Book Value of depreciable machinery retired during year

57.2

42.5

Total Gross Book Value of depreciable assets retired during year

39.7

56.6

43.4 
Appendix F - Mailout Response Rates by 2 digit SIC for 1992 CCI

Questionnaire

Item

Depreciation charges for

Structures and additions

Depreciation charges for Machinery

Total Depreciation charges

Total Inventory for 1991

Total Inventory for 1992

Value of speculative construction work

Value of construction work done for own use
SIC by Response Percent 1500

1600

1700
33.5

40.1

41.4

47.6

48.5

76.2

75.2
47.5

35.9

58.9

44.4

59.4

45.8

65.6

54.2

66.8

55.3

81.7

78.6

81.3

78.4
1st Qtr Construction Workers
74.4
84.2
80.6
2nd Qtr Construction Workers
74.3
84.4
80.6 
Appendix G - Percent of Mailout Total Accepted without edit or impute by 2 digit SIC for 1992 CCI

Questionnaire

SIC by Acceptance Rate

Item 1500 1600 1700

3rd Qtr Construction Workers

74.6

84.7

80.7

4th Qtr Construction Workers

74.2

84.3

80.3

1st Qtr Other Employees

73.6

83.9

79.6

2nd Qtr Other Employees

73.8

84.2

80.0

3rd Qtr Other Employees

74.0

84.5

80.2

4th Qtr Other Employees

73.5

84.0

80.0

Total 1st Qtr Employees

79.1

89.0

86.9

Total 2nd Qtr Employees

79.1

89.5

86.7

Total 3rd Qtr Employees

79.2

89.5

86.8

Total 4th Qtr Employees

79.1

89.5

86.8

Average Construction Workers

27.9

26.5

31.8

Average Other Employees

68.9

77.4

74.7

Average Total Employees

78.3

88.7

86.1

Sum of 4 Qtrs of

Construction Workers

36.2

53.9

Sum of 4 Qtrs of

Other Employees

35.4

53.5

40.3

Sum of 4 Qtrs of Total Employees

39.5

59.0

46.5

Other Employee Salaries

63.3

75.9

67.3

Construction Worker Wages

66.9

77.2

70.9 
Appendix G - Percent of Mailout Total Accepted without edit or impute by 2 digit SIC for 1992 CCI

Questionnaire

SIC by Acceptance Rate

Item 1500 1600 1700

Total Payroll

88.4

1st Qtr Payroll

53.6

68.1

55.6

Cost of Legally Required Programs

58.0

Cost of Voluntary Programs

41.5

57.8

46.0

Total Labor Costs for Fringe Benefits

39.9

59.9

Amount paid by establishment for work subcontracted out to other companies

87.9

Payments for components, materials and supplies 70.8

76.4

Electricity Costs

74.6

83.2

79.2

Natural Gas Costs

71.9

78.6

75.4

Gasoline and Diesel Fuel

Cost for on Highway

73.5

68.8

Gasoline and Diesel Fuel

Costs for off Highway

66.3

68.0

69.8

Other Fuels Cost

70.0

78.2

73.3

Payments for rental or

lease of machinery

66.5

54.2

Payments for rental or

lease of structures

48.3

65.6

54.2

Total payments for rental or lease

84.5

84.2

Selected Purchased Services for communications

67.4

55.0 
Selected Purchased Services for repairs to machinery and equipment

Selected Purchased Services

for repairs to structures

Total Selected Purchased Services

Receipts for Business work

Total Value of Construction

work done

Receipts for Construction work

Total Receipts

Net Construction Value

Percent of total construction value for work done on privately owned construction

Percent of total construction value for work done on Federally owned construction

Percent of total construction value for work done on state and locally owned construction

Percent of total construction value for work Subcontracted in from others

Gross Book Value of Depreciable Assets for structures and additions
47.7

65.1

53.7

78.0

82.0

81.4

64.2

72.9

69.1

62.6

73.6

67.6

61.3

75.9

71.6

0.1

0.1

0.1

58.0

71.1

64.5

49.0

57.6

55.1

16.9

28.5

22.4

21.0

50.8

30.1

48.4

68.5

56.9

$31.4 \quad 44.3$

33.5 


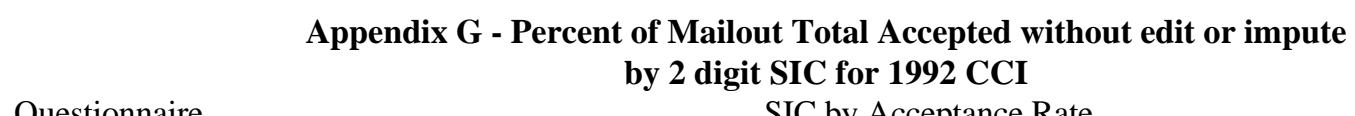

Questionnaire

SIC by Acceptance Rate

Item 1500 1600 1700

Gross Book Value of Depreciable Assets for machinery and equipment

48.4

36.0

Total Gross Book Value of

Depreciable Assets

Gross Book Value of Depreciable Assets for structures at beginning of year

51.6

39.8

Gross Book Value of Depreciable Assets for machinery at beginning of year

60.9

47.1

Total Gross Book Value of

Depreciable Assets at

beginning of year

41.6

59.2

46.1

Capital Expenditures for

New Structures

Capital Expenditures for

New Machinery

Capital Expenditures for

New Vehicles

40.1

56.5

Capital Expenditures for

Used Structures

46.1

36.5

Capital Expenditures for

Used Machinery

55.2

41.1

Gross Book Value of depreciable structures retired during year

46.0

Gross Book Value of depreciable 


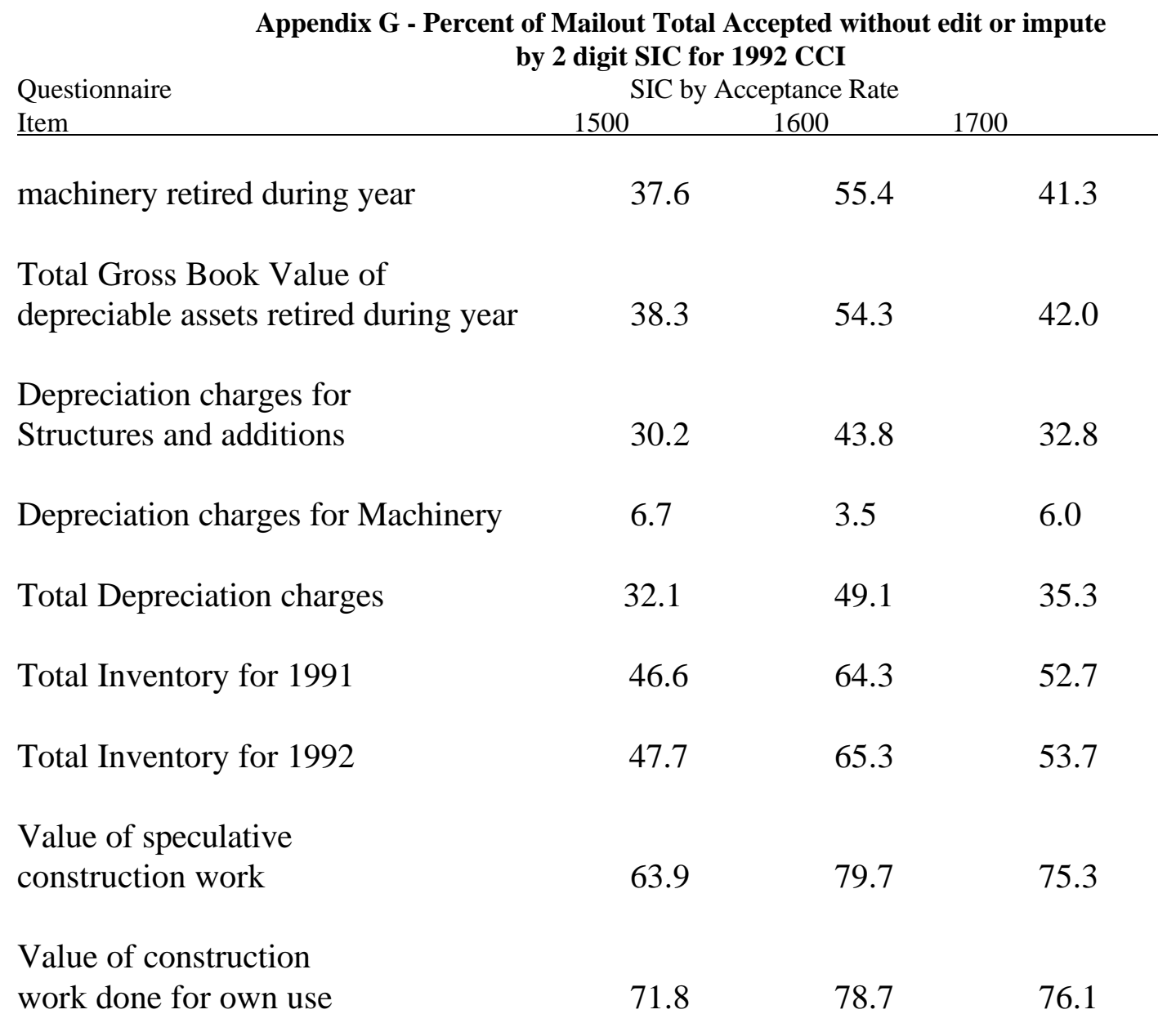

Profit Ratio

CY Payroll (Admin)

$0.113 \quad 10.0$

$422.1356 .5 \quad 1,986.81$

CY $1^{\text {st }}$ Qtr. Payroll (Admin)

$91.59 \quad 58.9$

CY $1^{\text {st }}$ Qtr. CBP Employment

Total Receipts in 1987

13.71

370.8

465.11

$1^{\text {st }}$ Qtr. Construction Workers

$2^{\text {nd }}$ Qtr. Construction Workers

10.41

$\begin{array}{ll}1,068.25 & 42.9\end{array}$

162.86

0.431

$3^{\text {rd }}$ Qtr. Construction Workers

$\begin{array}{lll} & 64.2 & \\ 11.50 & & 66.6 \\ 12.15 & & 61.0\end{array}$

48.48

$7,257.83$

51.17

49.75 


\begin{tabular}{|c|c|c|c|}
\hline $4^{\text {th }}$ Qtr. Construction Workers & 11.34 & 62.2 & 48.36 \\
\hline${ }^{1 \text { st }}$ Qtr. Other Workers & 3.36 & 70.6 & 15.36 \\
\hline $2^{\text {nd }}$ Qtr. Other Workers & 3.34 & 72.7 & 15.10 \\
\hline $3^{\text {rd }}$ Qtr. Other Workers & 3.36 & 69.3 & 14.95 \\
\hline $4^{\text {th }}$ Qtr. Other Workers & 3.33 & 63.3 & 14.68 \\
\hline Annual Other Workers Salaries & 125.4962 .5 & & 621.15 \\
\hline Construction Worker Wages & 290.9956 .8 & & $1,459.17$ \\
\hline Total Annual CY Payroll & 416.4957 .7 & & $1,967.77$ \\
\hline CY $1^{\text {st }}$ Qtr. Payroll & 80.41 & 59.3 & 464.39 \\
\hline \multicolumn{4}{|l|}{ Legally Required Labor } \\
\hline Benefits \& Costs & 59.90 & 48.1 & 328.98 \\
\hline \multicolumn{4}{|l|}{ Voluntary Labor } \\
\hline Benefits \& Costs & 37.51 & 45.4 & 271.32 \\
\hline Total Labor Costs (wage/salary) & 97.41 & 47.6 & 564.87 \\
\hline \multicolumn{4}{|l|}{ Amount of Work Subcontracted } \\
\hline To others & 512.2143 .0 & & $4,409.40$ \\
\hline \multicolumn{4}{|l|}{ Cost of Materials, Components } \\
\hline And Supplies & 524.6930 .2 & & $2,357.69$ \\
\hline Electricity Costs & 4.87 & 133.6 & 75.09 \\
\hline Natural Gas Costs & 1.66 & 271.6 & 32.99 \\
\hline Gas Costs (on-highway) & 12.97 & 56.7 & 61.15 \\
\hline Gas Costs (off-highway) & 6.37 & 78.6 & 73.40 \\
\hline Other Fuel Costs & 1.73 & 52.7 & 18.55 \\
\hline Rental/lease for machinery & 19.12 & 37.1 & 185.04 \\
\hline Rental/lease for structures & 7.43 & 64.2 & 49.61 \\
\hline Total Rental/lease payments & 26.54 & 34.3 & 203.66 \\
\hline Purchased Services - Comm. & 6.43 & 44.6 & 30.65 \\
\hline \multicolumn{4}{|l|}{ Purchased Services - Repairs } \\
\hline To machinery/equipment & 17.19 & 43.0 & 134.75 \\
\hline \multicolumn{4}{|l|}{ Purchased Services - Repairs } \\
\hline To structures & 1.41 & 63.9 & 16.56 \\
\hline Other Business Receipts & 40.78 & 177.0 & 913.91 \\
\hline Value of Construction Work & $1,831.75$ & 32.4 & $8,669.85$ \\
\hline Total Receipts & $1,872.53 \quad 34.7$ & & $9,016.02$ \\
\hline \multicolumn{4}{|l|}{ Percent of Construction Work } \\
\hline For Private Use & 0.71 & -1.0 & 0.41 \\
\hline \multicolumn{4}{|l|}{ Percent of Construction Work } \\
\hline For Federal Use & 0.02 & 6.7 & 0.10 \\
\hline \multicolumn{4}{|l|}{ Percent of Construction Work } \\
\hline For State/Local govt. & 0.08 & 3.2 & 0.20 \\
\hline $\begin{array}{l}\text { Gross Book Value of Depreciable } \\
\text { Assets - structures/adds. }\end{array}$ & 3387 & 4175 & 183915 \\
\hline
\end{tabular}


Gross Book Value of Depreciable

$$
\text { Assets - mach/equipment }
$$

198.74155 .2

$1,991.41$

Total Gross Book Value of

Depreciable Assets

232.61211 .2

$3,018.85$

Beginning of Year Gross Book

Value of Depreciable Assets -

Structures \& additions

33.53

409.1

$1,852.50$

Beginning of Year Gross Book

Value of Depreciable Assets -

Machinery \& equipment

Percent of Construction Value for

Maintenance and Repair

Beginning of Year Total Gross Book

Value of Depreciable Assets

Capital Expenditures for New

Structures

Capital Expenditures for New

Machinery

Capital Expenditures for New

Vehicles

Capital Expenditures for Used

Structures

Capital Expenditures for Used Machinery

Total Capital Expenditures

Gross Book Value of Depreciable

Structures Retired during year

Gross Book Value of Depreciable

Machinery retired during year 11.15

Total Gross Book Value of Depreciable

Assets retired during year

Depreciation charges for Structures

And additions

Depreciation charges for Machinery

Total Inventory for 1991

Total Inventory for 1992

Percent of Construction that is New

Percent of Construction Value for

Alterations and Additions

Percent of Construction Value for work
189.56155 .5

$1,969.39$

0.19

1.7

0.30

223.09212 .0

$3,012.45$

1.81

185.6

54.50

10.64

82.0

133.66

12.45

76.9

150.28

0.39

84.3

11.39

4.76

80.5

68.44

22.53

52.9

194.78

1.86

326.7

190.81

148.6

195.60

13.01

163.2

276.45

2.19

122.0

38.31

20.58

91.7

171.50

17.80

109.0

290.15

19.78

217.1

489.51

0.56

$-0.3$

0.40

0.25

1.2

0.32 
Appendix H - Unweighted Descriptive Statistics for Select Items for 1992 CCI (Dollar figures in thousands)

Variable Mean Skewness Standard Deviation

Performed in state in which

Establishment is located

0.97

$-5.2$

0.14

Number of states in which establishment

Did construction work

1.20

13.3

0.99

Value of Speculative Construction Work

151.0751 .8

$2,745.26$

Value of Construction Work done for

Own use

0.53

238.7

20.82 